\title{
Bias associated with delayed verification in test accuracy studies: accuracy of tests for endometrial hyperplasia may be much higher than we think!
}

\author{
T Justin Clark*1, Gerben ter Riet ${ }^{2}$, Aravinthan Coomarasamy ${ }^{1}$ and \\ Khalid S Khan ${ }^{1}$
} \begin{abstract}
Center, Department of General Practice, 1105 AZ, Amsterdam, Netherlands
Email: T Justin Clark* - justin.clark@bwhct.nhs.uk; Gerben ter Riet - G.terRiet@amc.uva.nl;

Aravinthan Coomarasamy - a.coomarasamy@bham.ac.uk; Khalid S Khan - khalid.khan@bwhct.nhs.uk

* Corresponding author
\end{abstract}

Address: ${ }^{1}$ Academic Department of Obstetrics \& Gynaecology, Birmingham Women's Hospital, Birmingham, B15 2TG, UK and ${ }^{2}$ Academic Medical

Published: II May 2004

BMC Medicine 2004, 2:18
Received: 16 September 2003

Accepted: II May 2004

This article is available from: http://www.biomedcentral.com/I74I-70I5/2/18

(C) 2004 Clark et al; licensee BioMed Central Ltd. This is an Open Access article: verbatim copying and redistribution of this article are permitted in all media for any purpose, provided this notice is preserved along with the article's original URL.

\begin{abstract}
Background: To empirically evaluate bias in estimation of accuracy associated with delay in verification of diagnosis among studies evaluating tests for predicting endometrial hyperplasia.

Methods: Systematic reviews of all published research on accuracy of miniature endometrial biopsy and endometr ial ultrasonography for diagnosing endometrial hyperplasia identified 27 test accuracy studies (2,982 subjects). Of these, 16 had immediate histological verification of diagnosis while II had verification delayed $>24 \mathrm{hrs}$ after testing. The effect of delay in verification of diagnosis on estimates of accuracy was evaluated using meta-regression with diagnostic odds ratio (dOR) as the accuracy measure. This analysis was adjusted for study quality and type of test (miniature endometrial biopsy or endometrial ultrasound).
\end{abstract}

Results: Compared to studies with immediate verification of diagnosis (dOR 67.2, 95\% Cl 21.7208.8), those with delayed verification ( $\mathrm{dOR} 16.2,95 \% \mathrm{Cl} 8.6-30.5)$ underestimated the diagnostic accuracy by $74 \%$ (95\% Cl 7\%-99\%; $P$ value $=0.048)$.

Conclusion: Among studies of miniature endometrial biopsy and endometrial ultrasound, diagnostic accuracy is considerably underestimated if there is a delay in histological verification of diagnosis.

\section{Background}

The natural history of endometrial hyperplasia is not fully understood [1]. What is known is that a proportion of simple and complex hyperplastic processes will regress without treatment [2] although the time scale over which such regression may occur is unclear. Similarly the time scale over which benign endometrium progresses to hyperplasia is also unknown. Among studies evaluating accuracy of tests for diagnosis of hyperplasia (miniature biopsy or ultrasonography), it has previously been hypothesised that if histological verification of diagnosis after performing the test is delayed, the estimation of test accuracy may be influenced by the phenomena of disease regression or progression [3]. For instance, false positive diagnoses of endometrial hyperplasia may occur due to natural disease regression during the time interval 
between testing and verification of diagnosis. Similarly, false negative diagnoses may also result from progression of benign functional or atrophic endometrium.

To obtain accurate estimates of test accuracy in studies of hyperplasia, an immediate comparison of the test under scrutiny with a reference standard that verifies the diagnosis will be essential [4-6]. When accuracy studies suffer from a delay in performance of the reference standard, the resultant false positives and false negatives will be expected to lead to an underestimation of test accuracy. In systematic reviews, when studies of various designs are collated, the extent of underestimation that arises from delay is important in obtaining an unbiased pooled accuracy estimate. To our knowledge, the extent of underestimation of accuracy due to a delay in verification of diagnosis has not been evaluated empirically in studies of endometrial hyperplasia. We undertook this analysis to examine formally how inaccurate the estimation of accuracy can be in studies evaluating miniature endometrial biopsy devices and endometrial thickness measurement by pelvic ultrasonography for predicting endometrial hyperplasia when there are delays in histological verification of diagnosis.

\section{Methods}

To test our hypothesis, a data set of all the published studies reporting the accuracy of miniature endometrial biopsy devices and endometrial ultrasonography for predicting endometrial hyperplasia was obtained from systematic reviews $[7,8]$. The reviews focused on test accuracy studies in which the results of the test were compared with the results of a reference standard. The targeted population was women with abnormal pre- or postmenopausal uterine bleeding. The diagnostic tests of interest were miniature endometrial biopsy devices (for example, pipelle ${ }^{\circledast}$ endometrial suction curette, Unimar, Wilton, CT, USA) and endometrial thickness measurement by pelvic ultrasonography. The reference standard was endometrial histology obtained by an independent endometrial sampling technique, for example, inpatient curettage (with hysteroscopy) or hysterectomy.

\section{Identification of studies}

Two independent electronic searches of MEDLINE and EMBASE were conducted to identify relevant citations on endometrial biopsy (1980-1999) and ultrasonography (1966-2000). Search term combination for endometrial biopsy [8] was diagnosis (MeSH) AND endometrial biopsy (textword), while that for studies on ultrasonography [7] was ultrasound AND endometrial thickness AND sonography (textwords). The searches were limited to human studies, but there were no language restrictions. Relevant studies were identified by examining all the retrieved citations, reference lists of all known reviews and primary studies, and direct contact with manufacturers. Details of the search and selection processes can be found in the published reports of the reviews $[7,8]$.

\section{Study quality assessment}

All selected studies were assessed for their methodological quality defined as the confidence that study design, conduct and analysis minimize bias in the estimation of diagnostic accuracy [9-11]. We considered the following features in quality assessment: method of recruitment of sample, appropriateness of patient spectrum, and blinding of comparison between test and reference standard. Recruitment was considered to be adequate if patient selection was consecutive or a random sample was obtained. Patient spectrum was considered to be appropriate if both pre- and postmenopausal women were included. Blinding was considered to be present if it was clearly reported that the pathologists providing histological reports were kept unaware of the results of miniature endometrial biopsy or endometrial ultrasonography. If the results of the diagnostic tests were divulged to the pathologists or in the absence of any such reporting, blinding was categorised as absent. For the purpose of our analysis, studies were classified into two quality categories: Category I studies had any one of the following features: adequate recruitment, appropriate spectrum, and blinding; category II studies had none of the above quality features.

\section{Data extraction}

In addition to assessment of methodological quality, data were extracted to allow classification of studies into one of two groups: i) immediate verification - reference standard performed within 24 hours of testing, and ii) delayed verification - reference standard performed more than 24 hours after testing. Any studies that could not be categorised in this way due to lack of reporting were excluded. Data were then abstracted as $2 \times 2$ tables and estimates of diagnostic accuracy were derived for each individual study. A correction factor of 0.5 was used when cells of the $2 \times 2$ tables included zero values [12]. True positive rates (sensitivity), false positive rates (1-specificity) and diagnostic odds ratios (dORs) were calculated for each primary evaluation. The dOR represents a ratio of the positive and negative likelihood ratios and it can be mathematically summarised as:

$\mathrm{dOR}=[$ sensitivity $/(1$-specificity $)] /[(1-$ sensitivity $) /$ specificity]

\section{Statistical analysis}

Pooled dORs were generated as the principal measures of diagnostic accuracy. Meta-analyses to produce summary estimates of accuracy were performed separately for subgroups of studies reporting immediate and delayed 
verification. To delineate the impact of delay in verification of diagnosis, weused meta-regression analysis $[13,14]$ with the log of dOR as the accuracy measure. This technique fitted a multivariable linear regression model for examining the influence of delay, quality and test type on the estimation of accuracy observed among studies included in the analysis (random effects model). In this way the analysis was adjusted for the confounding effects of study quality (two quality categories) and type of test (miniature endometrial biopsy or endometrial ultrasound).

\section{Results}

\section{Selection of studies}

The study selection process is shown in Figure 1. In total there were 2,982 subjects in 27 diagnostic evaluations reported in the 24 eligible primary studies. Eleven evaluations delayed verification of the diagnosis by more than 24 hours; the delay was up to six months in one study, up to four weeks in four studies, up to three weeks in one study and up to one week in the remaining three studies. Three of these studies were rated as category I for methodological quality, and eight as category II. Sixteen evaluations verified the diagnosis within 24 hours of the test. Among these, seven studies were rated as category I for quality, and nine as category II (Table 1).

Table 2 shows the diagnostic accuracy results for individual studies according to test type and verification status in terms of delay. The summary statistics for the various subgroups showed that the dOR for studies with immediate verification was $67.2(21.7-208.8)$ while that for studies with delayed verification was $16.2(8.6-30.5)$ as shown in Figure 2. Meta-regression analysis for bias due to delay in verification of diagnosis, adjusted for study quality and test type, showed that the underestimation of test accuracy among studies with delayed verification was 74\% (95\% CI $7 \%-99 \% ; P=0.048)$ on average compared to studies with immediate verification (Table 3 ).

\section{Discussion}

Our study shows empirically the magnitude of bias associated with delay in verification of diagnosis in test accuracy studies. Delay in verification of more than 24 hours was associated with a considerable underestimation of accuracy of miniature biopsy and endometrial ultrasonography in diagnosing endometrial hyperplasia. This supports the premise that the reported limited accuracy of miniature endometrial biopsy devices and endometrial ultrasonography in diagnosing hyperplasia is due, in part, to natural history of disease rather than resulting entirely from intrinsic problems with performance of the diagnostic tools [3].
We posed our hypothesis a priori and tested it in as rigorous a manner as possible. Our literature search was without language restriction, facilitating retrieval of many relevant test accuracy studies. However, due to poverty of reporting many critical pieces of information were missing in the available literature, restricting the number of studies that could be included in our analysis (for example, 31 studies were ineligible for inclusion because explicit information about time before verification was omitted). Our examination of delays in verification was also restricted; just two time categories were discernible (delay $<24$ hours or $>24$ hours). Immediate verification (reference standard to be performed straight after the index test) was not achievable in some studies because the reference test (inpatient endometrial sampling) necessitated use of general anaesthesia. A practical cut-off of 24 hours was taken to allow time for reference testing to be undertaken when the preceding index tests (miniature endometrial biopsy and ultrasound) were performed in the conscious outpatient. Although the natural history of endometrial hyperplasia is unclear, it is unlikely that biological alteration would have occurred within 24 hours. To study the rate of disease progression or regression would require repeated testing over time, but such a study is unlikely to be ethically justifiable, given that most clinicians will institute treatment following initial diagnosis. Such a study would be then become one of prognosis under treatment rather than a natural history study.

We also evaluated other features of methodological quality and, in general, found the quality of studies to be poor. For example, only three studies reported blinding interpretation of the reference test from knowledge of results from the index test. A lack of blinding can introduce bias and overestimation of diagnostic accuracy [4]. Pathological interpretation of endometrial hyperplasia is open to a varying degree of subjectivity especially at extreme ends of the spectrum, where overlap with benign functional endometrium (simple hyperplasia) and cancer (complex hyperplasia with cytological atypia) is more likely. Absence (or explicit reporting) of blinding is thus associated with poorer methodological quality and this feature was incorporated in our quality assessment. Our analysis adjusted for the confounding effects of quality but our inferences should be interpreted with caution due to relative scarcity of good quality studies.

\section{Conclusions}

Our findings have implications for research into new diagnostic interventions. Our results demonstrate that test evaluation with robust study design (immediate verification) showed good test performance but evaluation in poor designs (delayed verification) showed poor performance. Poor designs may reflect the situation prevalent in routine clinical practice where test results may not be 
Endometrial biopsy

Number of potentially eligible studies from search (see methods) $n=52$

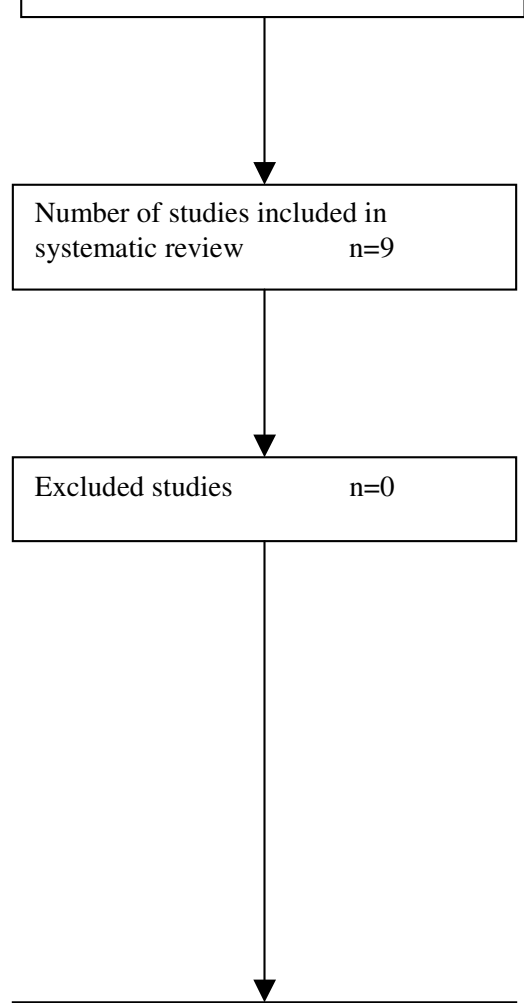

Number of studies (and evaluations) eligible for inclusion in present study $\mathrm{n}=9$ (12)
Ultrasound

Number of potentially eligible

studies from search $\quad \mathrm{n}=145$

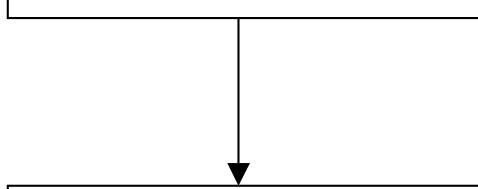

Number of studies included in systematic review

$\mathrm{n}=57$

Excluded studies

$\mathrm{n}=42$

Reason for exclusion from present study:

Reference standard not obtained by

an independent, endometrial

sampling technique $\quad \mathrm{n}=0$

Absence of explicit information on

time between test performance and

verification $n=$

31

Both of the above $\quad n=11$ eligible for inclusion in present study $\mathrm{n}=15$ (15)

Figure I

Flow diagram showing study selection process. 
Table I: Study characteristics and methodological quality.

\begin{tabular}{|c|c|c|c|c|c|c|c|c|c|c|}
\hline \multirow[b]{2}{*}{$\begin{array}{l}\text { Study (Year } \\
\text { published) }\end{array}$} & \multirow[b]{2}{*}{ Details } & \multirow[b]{2}{*}{$\begin{array}{l}\text { Delay } \\
\text { (hours) }\end{array}$} & \multirow[b]{2}{*}{$\begin{array}{l}\text { Patient } \\
\text { selection }\end{array}$} & \multicolumn{4}{|c|}{ Bleeding type / Menopausal status (\%) } & \multirow[b]{2}{*}{$\begin{array}{l}\text { Reference } \\
\text { standard }\end{array}$} & \multirow[b]{2}{*}{$\begin{array}{l}\text { Blinding } \\
\text { of results }\end{array}$} & \multirow[b]{2}{*}{$\begin{array}{l}\text { Study } \\
\text { quality } \\
\text { level }\end{array}$} \\
\hline & & & & Post & HRT & Pre & tOther & & & \\
\hline \multirow{2}{*}{\multicolumn{11}{|c|}{$\begin{array}{l}\text { IMMEDIATE VERIFICATION (</=24 HOURS) ( } 6 \text { studies) } \\
\text { Endometrial biopsy studies ( } 8 \text { ) }\end{array}$}} \\
\hline & & & & & & & & & & \\
\hline $\begin{array}{l}\text { Sun-Kuie et al. } \\
\text { [15] (1992) }\end{array}$ & Gynoscann $^{\circledR}$ & Day before & Unreported & $* 5(\mathrm{II})$ & - & $4 \mid(89)$ & - & $\mathrm{D \& C}$ & Unreported & 1 \\
\hline $\begin{array}{l}\text { Goldberg et al. } \\
\text { [16] (198I) }\end{array}$ & Accurette $^{\circledR}$ & Immediate & Unreported & $30(100)$ & - & & - & $\mathrm{D \& C}$ & Unreported & II \\
\hline $\begin{array}{l}\text { Sonnendecker } \\
\text { et al. [17] } \\
\text { (198I) }\end{array}$ & Accurette $^{\circledR}$ & Immediate & Unreported & *6 (24) & - & $17(76)$ & - & $\mathrm{D \& C}$ & Unreported & 1 \\
\hline $\begin{array}{l}\text { Kufahl et al. } \\
\text { [18] (1997) }\end{array}$ & Explora $^{\circledR}$ & Immediate & Consecutive & $* 33(21)$ & - & $125(79)$ & - & Hysterectomy & Unreported & 1 \\
\hline $\begin{array}{l}\text { Kufahl et al. } \\
\text { [18] (1997) }\end{array}$ & Gynoscann $^{\circledR}$ & Immediate & Consecutive & $* 36(2 I)$ & - & I 33 (79) & - & Hysterectomy & Unreported & 1 \\
\hline $\begin{array}{l}\text { Goldschmit et } \\
\text { al. [19] (1993) }\end{array}$ & Pipelle $^{\circledR}$ & Immediate & Consecutive & $* 34(23)$ & - & II 5 (77) & - & $\mathrm{D} \& \mathrm{C}$ & Yes & 1 \\
\hline $\begin{array}{l}\text { Kavak et al. } \\
{[20](1996)}\end{array}$ & Pipelle ${ }^{\circledR}$ & Immediate & Unreported & $* 34(56)$ & - & $27(44)$ & - & $\mathrm{D \& C}$ & Yes & 1 \\
\hline $\begin{array}{l}\text { Goldberg et al. } \\
{[16](1981)}\end{array}$ & $\begin{array}{l}\text { Vabra } \\
\text { Aspirator }^{\circledR}\end{array}$ & Immediate & Unreported & $31(100)$ & - & - & - & $\mathrm{D} \& \mathrm{C}$ & Unreported & II \\
\hline \multicolumn{11}{|c|}{ Ultrasound scan studies (8) } \\
\hline $\begin{array}{l}\text { Botsis et al. } \\
{[21](1992)}\end{array}$ & $\leq 4 \mathrm{~mm} \mathrm{DL}$ & Day before & Unreported & $120(100)$ & - & - & - & $\mathrm{D} \& \mathrm{C}$ & Unreported & II \\
\hline $\begin{array}{l}\text { Garuti et al. } \\
\text { [22] (1999) }\end{array}$ & $\leq 4 \mathrm{~mm} \mathrm{DL}$ & Immediate & Unreported & $368(88)$ & $\begin{array}{l}51 \\
(12)\end{array}$ & - & - & $D \& C$ & Unreported & 1 \\
\hline $\begin{array}{l}\text { Haller et al. } \\
{[23](1996)}\end{array}$ & $\leq 4 \mathrm{~mm} \mathrm{DL}$ & Day before & Unreported & $81(100)$ & - & - & - & $D \& C$ & Unreported & II \\
\hline $\begin{array}{l}\text { Grigoriou et al. } \\
\text { [24] (1996) }\end{array}$ & $\leq 5 \mathrm{~mm} \mathrm{DL}$ & Day before & Unreported & $250(100)$ & - & - & - & $D \& C$ & Unreported & II \\
\hline $\begin{array}{l}\text { Karlsson et al. } \\
{[25](1993)}\end{array}$ & $\leq 5 \mathrm{~mm} \mathrm{DL}$ & Day before & Unreported & $103(100)$ & - & - & - & $D \& C$ & Unreported & II \\
\hline $\begin{array}{l}\text { Malinova et al. } \\
\text { [26] (1996) }\end{array}$ & $\leq 5 \mathrm{~mm} \mathrm{DL}$ & Day before & Unreported & $154(100)$ & - & - & - & $D \& C$ & Unreported & II \\
\hline $\begin{array}{l}\text { Wolman et al. } \\
\text { [27] (1996) }\end{array}$ & $\leq 5 \mathrm{~mm} \mathrm{DL}$ & Immediate & Unreported & $54(100)$ & - & - & - & $D \& C$ & Unreported & II \\
\hline $\begin{array}{l}\text { Malinova et al. } \\
\text { [28] (1995) }\end{array}$ & $\leq 5 \mathrm{~mm} \mathrm{SL}$ & Day before & Unreported & $118(100)$ & - & - & - & $D \& C$ & Unreported & II \\
\hline \multicolumn{11}{|c|}{ DELAYED VERIFICATION (> 24 HOURS) (I I studies) } \\
\hline \multicolumn{11}{|c|}{ Endometrial biopsy studies (4) } \\
\hline $\begin{array}{l}\text { Stovall et al. } \\
\text { [29] (1989) }\end{array}$ & $\begin{array}{l}\text { Novak } \\
\text { Curette }^{\circledR}\end{array}$ & Unreported & Unreported & - & - & - & $165(100) N S$ & Hysterectomy & Unreported & II \\
\hline $\begin{array}{l}\text { Krampl et al. } \\
\text { [3] (1997) }\end{array}$ & Pipelle ${ }^{\circledR}$ & $<6$ months & Unreported & $37(12)$ & - & $247(77)$ & $35(11)$ & $\begin{array}{l}\text { TCRE/ } \\
\text { Hysterectomy }\end{array}$ & Unreported & 1 \\
\hline $\begin{array}{l}\text { Gupta et al. } \\
\text { [30] (1996) }\end{array}$ & Pipelle ${ }^{\circledR}$ & $<$ I month & Unreported & $54(100)$ & - & - & & $\mathrm{D} \& \mathrm{C}$ & Unreported & II \\
\hline $\begin{array}{l}\text { Stovall et al. } \\
\text { [29] (1989) }\end{array}$ & $\begin{array}{l}\text { Vabra } \\
\text { Aspirator }^{\circledR}\end{array}$ & Unreported & Unreported & - & - & - & $62(100)$ NS & Hysterectomy & Unreported & II \\
\hline
\end{tabular}


Table I: Study characteristics and methodological quality. (Continued)

\begin{tabular}{|c|c|c|c|c|c|c|c|c|c|c|}
\hline \multicolumn{11}{|c|}{ Ultrasound scan studies (7) } \\
\hline $\begin{array}{l}\text { Guner et al. } \\
{[31](1996)}\end{array}$ & $\leq 4 \mathrm{~mm} \mathrm{DL}$ & $</=7$ days & Unreported & $192(100)$ & - & - & - & $D \& C$ & Unreported & II \\
\hline $\begin{array}{l}\text { Abu-Ghazzeh } \\
\text { et al. [32] } \\
\text { (1999) }\end{array}$ & $\leq 5 \mathrm{~mm} \mathrm{DL}$ & I week & Unreported & $98(100)$ & - & - & - & $D \& C$ & Unreported & II \\
\hline $\begin{array}{l}\text { DeSilva et al. } \\
\text { [33] (1997) }\end{array}$ & $\leq 5 \mathrm{~mm} \mathrm{DL}$ & $<4$ weeks & Consecutive & $44(88)$ & $6(12)$ & - & - & $D \& C$ & Unreported & I \\
\hline $\begin{array}{l}\text { Gupta et al. } \\
\text { [30] (1996) }\end{array}$ & $\leq 5 \mathrm{~mm} \mathrm{DL}$ & $<$ I month & Unreported & $75(100)$ & - & - & - & $D \& C$ & Yes & I \\
\hline $\begin{array}{l}\text { Taviani et al. } \\
\text { [34] (1995) }\end{array}$ & $\leq 5 \mathrm{~mm} \mathrm{DL}$ & I week & Unreported & $4 I(100)$ & - & - & - & $D \& C$ & Unreported & II \\
\hline $\begin{array}{l}\text { Moreles et al. } \\
\text { [35] (1998) }\end{array}$ & $\leq 6 \mathrm{~mm} \mathrm{DL}$ & $<3$ weeks & Unreported & $200(100)$ & - & - & - & $D \& C$ & Unreported & II \\
\hline $\begin{array}{l}\text { Mortakis et al. } \\
\text { [36] (1997) }\end{array}$ & $\leq 3 \mathrm{~mm} \mathrm{SL}$ & $<4$ weeks & Unreported & $78(100)$ & - & - & - & $D \& C$ & Unreported & II \\
\hline
\end{tabular}

*Numbers calculated from initial proportion of patients within these groups before missing outcome data was excluded. tOther refers to proportion of women included in the study who did not have abnormal uterine bleeding as an indication for investigation. HRT, hormone replacement therapy; NS, not specified (refers to proportion of women included in the study where the type of abnormal uterine bleeding was not specified); DB, directed biopsy; D\&C, dilatation and curettage; TCRE, transcervical resection of the endometrium; DL, double layer endometrial thickness; SL, single layer endometrial thickness.

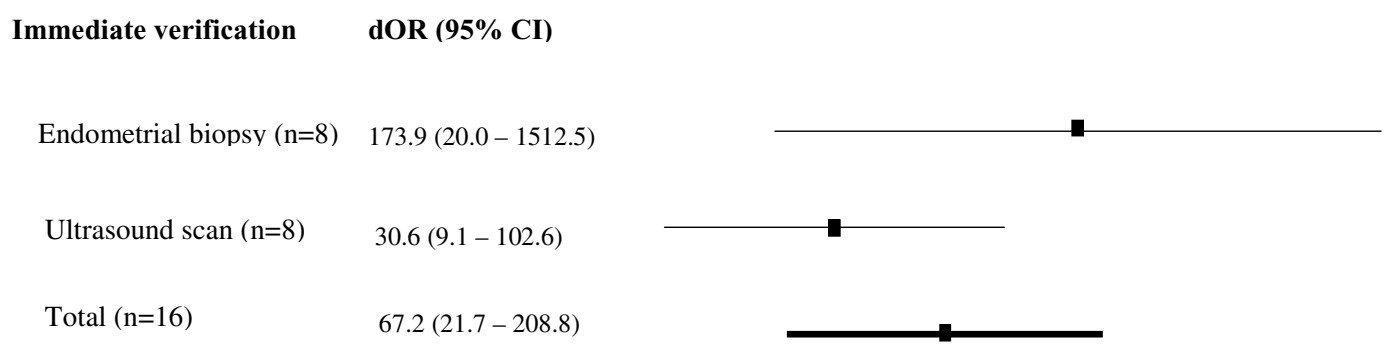

Delayed verification
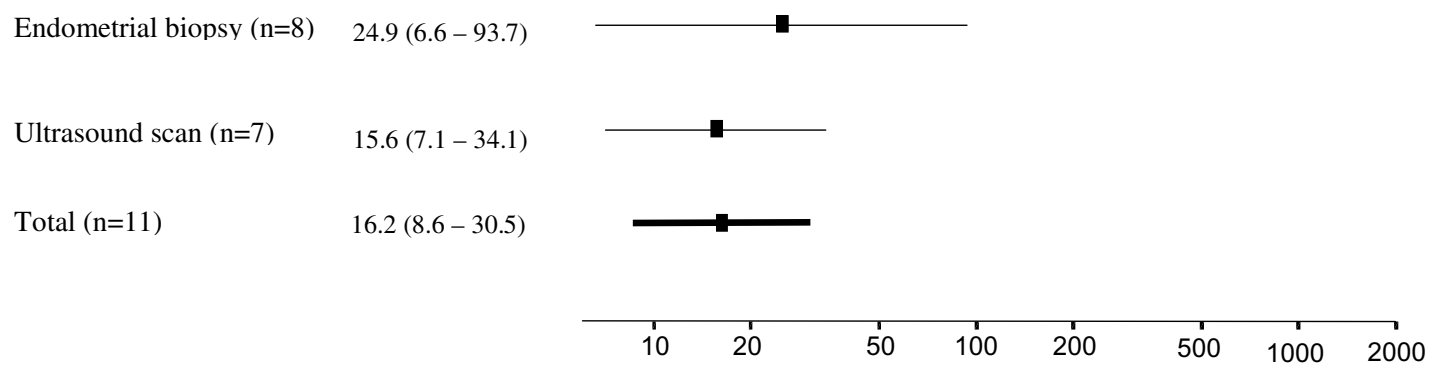

DOR (logarithmic scale)

\section{Figure 2}

Effect of delayed verification on the diagnostic accuracy of miniature endometrial biopsy and transvaginal ultrasound in detecting endometrial hyperplasia. Pooled diagnostic odds ratios (dOR) for studies with immediate and delayed verification. 
Table 2: Accuracy stratified by time delay between test performance and confirmation by chosen reference test histology.

\begin{tabular}{|c|c|c|c|}
\hline $\begin{array}{l}\text { Device (no. evaluations) \& } \\
\text { study (year published) }\end{array}$ & +ve test (sensitivity) & -ve test (I-specificity) & Odds ratio $(95 \% \mathrm{Cl})$ \\
\hline \multicolumn{4}{|c|}{ IMMEDIATE VERIFICATION (</= 24 HOURS) ( 6 studies) } \\
\hline Sun-Kuie et al. $[15](1992)$ & $2 / 4(0.5)$ & $0 / 42(0.0)$ & $85.0(3.2-2289.6)$ \\
\hline Goldberg et al. [16] (198I) & $5 / 5(1.0)$ & $0 / 25(0.0)$ & $561.0(10.0-3 \mid 463.1)$ \\
\hline Sonnendecker et al. [17] (198I) & $2 / 2(1.0)$ & $0 / 21(0.0)$ & $215.0(3.5-13408.5)$ \\
\hline Kufahl et al. [18] (1997) & $14 / 15(0.9)$ & $4 / 143(0.03)$ & $486.5(50.8-4658.5)$ \\
\hline Kufahl et al. $[18](1997)$ & $3 / 15(0.2)$ & $15 / 154(0.1)$ & $2.3(0.6-9.1)$ \\
\hline Goldschmit et al. [19] (1993) & $11 / 14(0.8)$ & $1 / 135(0.01)$ & $491.3(47.1-5 \mid 27.3)$ \\
\hline Kavak et al. [20] (1996) & $4 / 4(1.0)$ & $0 / 57(0.0)$ & $1035.0(18.3-58563.1)$ \\
\hline Goldberg et al. [16] (198I) & $6 / 6(1.0)$ & $0 / 25(0.0)$ & $663.0(12.0-36690.0)$ \\
\hline \multicolumn{4}{|l|}{ Ultrasound scan studies (8) } \\
\hline Botsis et al. [21] (1992) & $10 / 10(1.0)$ & $4 / 92(0.04)$ & $413.0(20.8-8221.1)$ \\
\hline Garuti et al. [22] (1999) & $44 / 46(0.96)$ & $196 / 313(0.63)$ & I3.I (3.|-55.2) \\
\hline Haller et al. [23] (1996) & $14 / 16(0.88)$ & $34 / 49(0.69)$ & $3.1(0.6-15.3)$ \\
\hline Grigoriou et al. [24] (1996) & $45 / 45(0.98)$ & $30 / 181(0.17)$ & $452.0(27.1-7538.5)$ \\
\hline Karlsson et al. [25] (1993) & $10 / 10(1.0)$ & $21 / 78(0.27)$ & $56.2(3.2-1000.5)$ \\
\hline Malinova et al. [26] (1996) & $I I / I I(I .0)$ & $32 / 74(0.43)$ & $30.1(1.7-529.5)$ \\
\hline Wolman et al. [27] (1996) & $10 / 11(0.91)$ & $12 / 39(0.31)$ & $22.5(2.6-196.1)$ \\
\hline Malinova et al. [28] (1995) & $7 / 7(1.0)$ & $19 / 54(0.35)$ & $27.31(1.5-504.1)$ \\
\hline \multicolumn{4}{|c|}{ DELAYED VERIFICATION (> 24 HOURS) (I I studies) } \\
\hline \multicolumn{4}{|c|}{ Endometrial biopsy studies (4) } \\
\hline Stovall et al. [29] (1989) & $8 / 16(0.5)$ & $4 / 149(0.03)$ & $36.3(9.0-146.3)$ \\
\hline Krampl et al. [3] (1997) & $14 / 35(0.4)$ & $24 / 284(0.0)$ & $7.2(3.3-16.0)$ \\
\hline Gupta et al. [30] (1996) & $6 / 10(0.6)$ & $\mathrm{I} / 44(0.02)$ & $64.5(6.1-677.6)$ \\
\hline Stovall et al. [29] (1989) & $7 / 7(1.0)$ & $7 / 55(0.13)$ & $97.0(5.0-1879.9)$ \\
\hline \multicolumn{4}{|l|}{ Ultrasound scan studies (7) } \\
\hline Guner et al. [31] (1996) & $3|/ 3|(1.0)$ & $61 / 142(0.43)$ & $83.5(5.0-1391.3)$ \\
\hline Abu-Ghazzeh et al. [32] (1999) & $2 / 2(1.0)$ & $58 / 95(0.61)$ & $3.2(0.2-68.6)$ \\
\hline DeSilva et al. [33] (1997) & $2 / 3(0.67)$ & $10 / 44(0.23)$ & $6.8(0.6-83.0)$ \\
\hline Gupta et al. [30] (1996) & $4 / 4(1.0)$ & $22 / 68(0.32)$ & $18.6(1.0-360.7)$ \\
\hline Taviani et al. [34] (1995) & $2 / 2(1.0)$ & 16/37 (0.43) & $6.5(0.3-145.1)$ \\
\hline Moreles et al. [35] (1998) & $33 / 37(0.9)$ & $37 / 143(0.26)$ & $23.6(7.8-71.2)$ \\
\hline Mortakis et al. [36] (1997) & $4 / 5(0.8)$ & $26 / 66(0.39)$ & $6.2(0.7-58.2)$ \\
\hline
\end{tabular}

Table 3: Results of meta-regression analysis.

\begin{tabular}{|c|c|c|c|c|}
\hline \multirow[t]{2}{*}{ Outcome Explanatory variables } & \multicolumn{2}{|c|}{ Univariable analysis } & \multicolumn{2}{|c|}{ Multivariable analysis } \\
\hline & Ratio dOR $(95 \% \mathrm{Cl})^{\dagger}$ & $P$ value & Ratio dOR $(95 \% \mathrm{Cl})^{\dagger}$ & $P$ value \\
\hline \multicolumn{5}{|l|}{ Endometrial hyperplasia } \\
\hline - Delay in verification of diagnosis ( $>24$ hours vs. $<24$ hours) & $0.31(0.08-0.84)$ & 0.089 & $0.26(0.07-0.99)$ & 0.048 \\
\hline - Study quality (category II vs. category I) & $1.36(0.34-5.53)$ & 0.664 & $3.46(0.79-15.0)$ & 0.098 \\
\hline - Test (Endometrial biopsy vs. ultrasound endometrial thickness) & $3.22(0.83-12.55)$ & 0.091 & $5.0(1.2-20.7)$ & 0.027 \\
\hline
\end{tabular}

tThe dependent variable is the natural logarithm of the diagnostic odds ratio (dOR). Results are presented as the ratio of diagnostic odds ratios $(\mathrm{RdOR})$; an RdOR < I means that the diagnostic accuracy is reduced and a RdOR > I means that it is increased in relation to the reference category, $<24 \mathrm{~h}$, category l, and ultrasound endometrial thickness, respectively.

immediately confirmed due to resource and other implications. Thus diagnostic evaluations carried out in routine practice may mask the accuracy of tests.

\section{Competing interests}

None declared. 


\section{Authors' contributions}

TJC and KSK conceived and designed the study with input from GtR. TJC conducted the systematic review and acquired all data. AC conducted the statistical analyses with input from KSK and GtR. TJC wrote all versions of the manuscript. KSK and GtR critically revised the manuscript for important intellectual content. All authors read and approved the final manuscript.

\section{References}

I. Fox H: Endometrial hyperplasia: a conceptual and practical approach. Gynaecology Forum 1996, I:7-9.

2. Kurman RJ, Kaminski PF, Norris HJ: The behaviour of endometrial hyperplasia: a long-term study of "untreated" hyperplasia in 170 patients. Cancer 1985, 56:403-4I2.

3. Krampl E, Soby B, Istre O: How representative are pipelle endometrial biopsies? A retrospective analysis of 324 biopsies followed by transcervical resection of the endometrium or hysterectomy. Gynaecol Endosc 1997, 6:277-28I.

4. Lijmer JG, Mol BW, Heisterkamp S, Bonsel G], Prins MH, Van der Meulen JHP, Bossuyt PM: Empirical evidence of design-related bias in studies of diagnostic tests. JAMA 1999, 282: 106I-1066.

5. Reid MC, Lachs MS, Feinstein AR: Use of methodological standards in diagnostic test research. Getting better but still not good. JAMA 1995, 274:645-65I.

6. Sheps SB, Schechter MT: The assessment of diagnostic tests: a survey of current medical research. JAMA I 984, 252:24I 8-2422.

7. Gupta JK, Chien PF, Voit D, Clark TJ, Khan KS: Ultrasonographic endometrial thickness for diagnosing endometrial pathology in women with postmenopausal bleeding: a meta-analysis. Acta Obstet Gynecol Scand 2002, 8 I:799-8I6.

8. Clark TJ, Mann CH, Shah N, Song F, Khan KS, Gupta JK: Accuracy of outpatient endometrial biopsy in the diagnosis of endometrial hyperplasia: a systematic quantitative review. Acta Obstet Gynecol Scand 200I, 80:784-793.

9. Cochrane Methods Working Group on Systematic Reviews of Screening and Diagnostic Tests: Recommended Methods [http://www.cochrane.org/cochrane/sadtdocl.htm]

10. Dunn G, Everitt B: Clinical Biostatistics. London: Edward Arnold 1995.

II. Khan KS, ter Riet G, Popay J, Nixon J, Kleijnen J: Study quality assessment. In Undertaking Systematic Reviews of Research on Effectiveness. CRD's Guidance for Carrying Out or Commissioning Reviews 2nd edition. Edited by: Khan KS, Ter Riet G, Glanville J, Sowden AJ, Kleijnen J. York: NHS Centre for Reviews and Dissemination (CRD), University of York; 2001.

12. Sankey S, Weisfiels L, Fine M, Kapoor W: An assessment of the use of the continuity correction for sparse data in meta analysis. Comm Stat Sim Comput 1996, 25:1031-1056.

13. Sterne JAC, Egger M, Davey Smith G: Investigating and dealing with publication and other biases. In Systematic Reviews in Health Care: Meta-analysis in Context Edited by: Egger M, Davey Smith G, Altman DG. London: BMJ Publishing Group; 2001:189-208.

14. Song F, Sheldon T, Sutton A, Abrams K, Jones D: Methods for exploring heterogeneity in meta-analysis. Eval Health Prof 200I, 24:|26-|5|.

15. Sun-Kuie T, Sian-Ann T, Ka-Mui C, Soo-Kim L: The diagnostic value and patient acceptability of outpatient endometrial sampling with Gynoscann. Aust NZ J Obstet Gynaecol 1992, 32:73-76.

16. Goldberg GL, Tsalacopoulos GDDA: A comparison of the Accurette and Vabra aspirator and uterine curettage. $S$ Afr Med J 1982, 6I: I| $4-1 \mid 6$.

17. Sonnendecker EW, Sevitz H, Hofmeyr GJ: Diagnostic accuracy of the accurette endometrial sampler. S Afr Med J 1982, 61:109-113.

18. Kufahl J, Pederson I, Eriksen PS, Helkjaer PE, Larsen LG, Jensen KL, de Nully P, Philipsen T, Wahlin A.: Transvaginal ultrasound, endometrial cytology sampled by Gynoscann and histology obtained by Uterine Explora Curette compared to the histology of the uterine specimen. A prospective study in preand postmenopasual women undergoing elective hysterectomy. Acta Obstet Gynecol Scand 1997, 76:790-796.
19. Goldchmit R, Katz Z, Blickstein I, Caspi B, Dgani R: The accuracy of endometrial Pipelle sampling with and without sonographic measurement of endometrial thickness. Obstet Gynecol 1993 , 82:727-730.

20. Kavak Z, Ceyhan N, Pekin S: Combination of vaginal ultrasonography and pipelle sampling in the diagnosis of endometrial disease. Aust N Z J Obstet Gynaecol 1996, 36:63-66.

21. Botsis D, Kassanos D, Pyrgiotis E, Zourlas PA: Vaginal sonography of the endometrium in postmenopausal women. Clin Exp Obstet Gynecol 1992, 19:189-192.

22. Garuti G, Sambruni I, Cellani F, Garzia D, Alleva P, Luerti M: Hysteroscopy and transvaginal ultrasonography in postmenopausal women with uterine bleeding. Int J Gynaecol Obstet 1999, 65:25-33.

23. Haller H, Matejcic N, Rukavina B, Krasevic M, Rupcic S, Mozetic D: Transvaginal sonography and hysteroscopy in women with postmenopausal bleeding. Int J Gynecol Obstet 1996, 54:155-I59.

24. Grigoriou O, Kalovidouros A, Papadias C, Antoniou G, Antonaki V, Giannikos L: Transvaginal sonography of the endometrium in women with postmenopausal bleeding. Maturitas 1996, 23:9-14

25. Karlsson B, Granberg S, Wikland M, Ryd W, Norstrom A: Endovaginal scanning of the endometrium compared to cytology and histology in women with postmenopausal bleeding. Gynecol Oncol 1993, 50:173-178.

26. Malinova M, Pehlivanov B: Transvaginal sonography and progesterone challenge for identifying endometrial pathology in postmenopausal women. Int J Gynecol Obstet 1996, 52:49-53.

27. Wolman I, Sagi J, Ginat S, Jaffa AJ, Hartoov J, Jedwab G: The sensitivity and specificity of vaginal sonography in detecting endometrial abnormalities in women with postmenopausal bleeding. I Clin Ultrasound 1996, 24:79-82

28. Malinova M, Pehlivanov $B$ : Transvaginal sonography and endometrial thickness in patients with postmenopausal uterine bleeding. Eur J Obstet Gynecol Reprod Biol 1995, 58:161-165.

29. Stovall TG, Solomon SK, Ling FW: Endometrial sampling prior to hysterectomy. Obstet Gynecol 1989, 73:405-409.

30. Gupta JK, Wilson S, Desai P, Hau C: How should we investigate women with postmenopausal bleeding? Acta Obstet Gynecol Scand 1996, 75:475-479.

31. Guner H, Tiras MB, Karabacak O, Sarikaya H, Erdem M, Yildirim M Endometrial assessment by vaginal ultrasonography might reduce endometrial sampling in patients with postmenopausal bleeding: A prospective study. Aust N Z J Obstet Gynaecol 1996, 36: I75-I78.

32. Abu-Ghazzeh Y, Shakoury WA, Barqawi R: Comparative study of transvaginal hysterosonography and biopsy for the evaluation of post-menopausal bleeding. Ann Saudi Med 1999, 19:116-119.

33. De Silva BY, Stewart K, Steven JD, Sathanandan M: Transvaginal ultrasound measurement of endometrial thickness and endometrial pipelle sampling as an alternative diagnostic procedure to hysteroscopy and dilatation and curettage in the management of post-menopausal bleeding. J Obstet Gynaecol 1997, 17:399-402.

34. Taviani A, Braccini S, Toniazzi P, Pantani P, Costamagna V, Gambini G, Pancanti $V$ : Transvaginal echography in patients with postmenopausal metrorrhagia. Minerva Ginecol 1995, 47:369-372.

35. Morales FJ, Dualde D, Marinaro A: Value of vaginal ultrasound in the diagnosis of postmenopausal metrorrhagia. Radiologia 1998, 40:255-262.

36. Mortakis AE, Mavrelos $\mathrm{K}$ : Transvaginal ultrasonography and hysteroscopy in the diagnosis of endometrial abnormalities. J Am Assoc Gynecol Laparosc 1997, 4:449-452.

\section{Pre-publication history}

The pre-publication history for this paper can be accessed here:

http://www.biomedcentral.com/1741-7015/2/18/prepub 